\title{
К ВОПРОСУ О КРИМИНАЛИЗАЦИИ МАССОВОГО РАСПРОСТРАНЕНИЯ ЭКСТРЕМИСТСКИХ МАТЕРИАЛОВ: НЕКОТОРЫЕ ДИСКУССИОННЫЕ АСПЕКТЫ
}

\begin{abstract}
Аннотация. Статья посвящена вопросу криминализации массового распространения экстремистских материалов. Автором анализируются материалы судебной практики по уголовным делам о преступлениях, предусмотренных сm. 282 УК РФ, и по административным делам о правонарушениях, предусмотренных cm. 20.29 КоАП РФ. Констатируется, что в следственной и судебной практике возникают определенные сложности в отграничении указанного правонарушения от преступления, предусмотренного ст. 282 УК РФ. Вопрос о размежевании данных запрещенных деяний в “пограничных зонах» относится к одним из наиболее сложных вопросов в правоприменительной деятельности. Методологической основой настоящего исследования служат базовые положения диалектического метода познания явлений и процессов объективной действительности. Также в работе использовались современные общенаучные, частнонаучные и специальные методы исследования: логико-юридический, сравнительно-правовой, системно-структурного анализа и др. Проведенное исследование позволило выявить ряд недостатков в антиэкстремистском законодательстве, а также в процедуре формирования и содержании федерального списка экстремистских материалов. В частности, дважды предметом судебного рассмотрения становится фрактически один и тот же информационный материал, правда выраженный в другой объективной форме, и закрепленный на ином носителе информации. Наличие такой возможности "обхода» закона рассредоточивает силы по противодействию экстремизму, и необоснованно расширяет федеральный список экстремистских материалов. Автором вносятся конкретные предложения по совершенствованию законодательства, позволяющие избежать множественности судебных решений по одним и тем же вопросам. Делается вывод, что обязательным условием реализации предложения о криминализации массового распространения экстремистских материалов является систематизация и анализ материалов, признанных экстремистскими, и включенных в опубликованный федеральный список экстремистских материалов. Обосновывается вывод о необходимости решения вопроса о создании так называемого “белого» списка информационных материалов, в который должны быть включены материалы, в отношении которых судом вынесено решение об отказе в признании их экстремистскими.
\end{abstract}

Ключевые слова: экстремистская деятельность, федеральный список, преступление, уголовное право, криминализация, экстремистские материалы, экстремизм, информация, публикация, возбуждение ненависти.

Abstract. The paper is devoted to criminalization of mass distribution of extremist materials. The author analyzes the judicial practice materials on criminal cases regulated by the article 282 of the Criminal Code of the Russian Federation, and on administrative cases regulated by the article 20.29 of the Code of Administrative Offences. The author states that investigative and judicial practice faces particular difficulties when distinguishing the mentioned offence from the crime established under the article 282 of the CC. The problem of distinguishing these illegal actions in the "border areas" is one of the most complicated problems of law enforcement. The research methodology is based on the general principles of the dialectical method. The author applies modern general scientific and specific research methods including logical and legal, comparative-legal, system-structural analysis and others. The author reveals certain shortcomings of anti-extremist legislation and the procedure of formation and the content of the federal list of extremist materials. Particularly, one and the same information material can be examined by court twice if it is represented in another form and fixed on another information carrier. The presence of such a possibility of avoidance of law disperses anti-extremist instruments and unreasonably extends the federal list of extremist materials. The author offers the ways to improve the legislation which can allow avoiding the multiplicity of judicial opinions on the alike issues. The author concludes that the necessary precondition of implementation of the suggestion about criminalization of mass distribution of extremist materials is systematization and analysis of extremist materials included in the published federal list. The author states that it is necessary to establish the so-called "white list" of information materials which should contain the materials which had been declared non-extremist by court.

Key words: extremist materials, criminalization, criminal law, crime, federal list, extremist activity, information, publication, hate mongering, extremism. 


\section{Административное и муниципальное право 8 (104) 2016}

$\mathrm{B}$ соответствии с п. 1 ст. 1 Федерального закона от 25 июля 2002 г. № 114-Ф3 «0 противодействии экстремистской деятельности» (далее Федеральный закон № 114-Ф3) одной из форм экстремистской деятельности (экстремизма) является «массовое распространение заведомо экстремистских материалов, а равно их изготовление или хранение в целях массового распространения» [1].

Несмотря на отсутствие единства употребляемых законодателем терминов, данная форма экстремистской деятельности подпадает под признаки административного правонарушения (ст. 20.29 КоАП РФ). В юридической литературе неоднократно высказывались предложения [2, с. 8; 3, с. 11] о необходимости криминализации массового распространения экстремистских материалов. Этот вопрос не раз становился предметом обсуждения и в Государственной Думе РФ. Рассматриваемое деяние относится к числу уголовно наказуемых в таких государствах как Великобритания, ФРГ, Сингапур, Индия, Узбекистан, Кыргызская Республика. Вместе с тем в его криминализации имеются определенные различия [4, с. 134].

В следственной и судебной практике возникают определенные сложности в отграничении указанного правонарушения от преступления, предусмотренного ст. 282 УК РФ. Вопрос о размежевании данных запрещенных деяний в «пограничных зонах» относится к одним из наиболее сложных вопросов в правоприменительной деятельности. Для его решения необходимо сопоставить соответствующие нормы административного и уголовного права.

Правонарушение, предусмотренное ст. 20.29 КоАП РФ, расположено в главе 20 «Административные правонарушения, посягающие на общественный порядок и общественную безопасность». Таким образом, объектом вышеуказанного правонарушения является общественный порядок и общественная безопасность. Преступление, предусмотренное ст. 282 УК РФ, расположено в разделе $\mathrm{X}$ «Преступления против государственной власти» главе 29 «Преступления против основ конституционного строя и безопасности государства» УК РФ. Следовательно, родовым объектом вышеуказанного преступления является государственная власть, а видовым - основы конституционного строя и безопасность государства. Изложенное позволяет сделать единственно верный вывод, что рассматриваемые общественно опасные деяния посягают на различные объекты.

Однако необходимо отметить, что вопрос об объекте преступления, предусмотренного ст. 282 УК РФ, относится к числу дискуссионных [5, с. 105106]. Так, ещё В.Д. Меньшагин, комментируя ст. 74 УК РСФСР 1960 г., регламентирующую ответствен- ность за деяние, аналогичное анализируемому преступлению, относил его к преступлениям, посягающим на основы общественной безопасности, и отмечал, что вследствие его совершения возникает скорее угроза совершения массовых беспорядков [6, с. 187]. В свою очередь объектом последнего преступления является именно общественный порядок как специальный компонент общественной безопасности. Кроме того считаем, что практически любое преступное проявление экстремизма, в первую очередь ставит под угрозу именно общественную безопасность. Ярким доказательством сказанного являются события, произошедшие в г. Кондопога в ночь с 30 августа 2006 г. Результатом массовой драки на межнациональной почве стало убийство двух местных жителей и причинение еще нескольким лицам колото-резаных ранений. Следствием этих событий стало проведение 2 сентября 2006 г. несанкционированного митинга с участием до двух тысяч человек. В ходе данного митинга высказывались требования о выдворении за пределы района выходцев с Кавказа, об отказе им в предоставлении социальных прав и возможности ведения коммерческой деятельности. Далее митинг перешел в погромы соответствующих торговых точек [5, с. 105-106].

Изложенное подтверждает, что объект посягательства является ненадежным разграничительным критерием в рассматриваемых случаях.

Объективная сторона преступления, предусмотренного ст. 282 УК РФ, заключается в совершении двух альтернативных действий:

a) действий, направленных на возбуждение ненависти либо вражды по одному или нескольким из нижеперечисленных признаков: пол, раса, национальность, язык, происхождение, отношение к религии, принадлежность к какой-либо социальной группе;

б) действий, направленных на унижение достоинства человека либо группы лиц по тем же признакам.

Как видим, диспозиция ст. 282 УК РФ сформулирована таким образом, что любые действия, направленные на возбуждение ненависти либо вражды, а также на унижение достоинства человека либо группы лиц по тем или иным признакам составляют объективную сторону преступления.

В ходе проведенного анализа материалов уголовных дел, возбужденных по ст. 282 УК РФ, мы сделали вывод, что самыми распространенными способами совершения данного преступления являются распространение материалов, содержащих негативную информацию в сети «Интернет», и распространение листовок и других печатных материалов, включающие: 
a) распространение автором своих собственных идей;

б) распространение материалов иных лиц [4, c. 120-121].

Объективная сторона правонарушения, предусмотренного ст. 20.29 КоАП РФ, выражается в том, что лицо совершает массовое распространение экстремистских материалов. Под массовым распространением экстремистских материалов следует понимать деятельность, направленную на ознакомление с экстремистскими материалами неопределенного круга потенциальных потребителей информации (зрителей, читателей, радиослушателей, телезрителей и т.д.) [9, с. 189-198].

Таким образом, объективная сторона рассматриваемого административного правонарушения идентична объективной стороне преступления, предусмотренного ст. 282 УК РФ.

Субъективная сторона преступления, предусмотренного ст. 282 УК РФ, характеризуется специальными целями. Цель является конститутивным элементом вышеуказанного преступления, а, следовательно, необходимым условием наступления уголовной ответственности. В диспозиции ст. 282 УК РФ цель определена как возбуждение ненависти либо вражды, а равно унижение достоинства человека либо группы лиц по признакам пола, расы, национальности, языка, происхождения, отношения к религии, а равно принадлежности к какой-либо социальной группе.

Субъективная сторона административного правонарушения, предусмотренного ст. 20.29 КоАП РФ, характеризуется прямым умыслом: лицо осознает противоправность своих действий, предвидит, что в результате их будет нарушен общественный порядок и общественная безопасность, и желает этого.

Таким образом, единственным разграничительным критерием рассматриваемых общественно опасных деяний является направленность умысла лица, распространяющего экстремистские материалы. Этой же позиции придерживается и Пленум Верховного Суда РФ в п. 8 своего постановления от 28 июня 2011 г. № 11 «О судебной практике по уголовным делам о преступлениях экстремистской направленности» [7].

Вместе с тем следует отметить, что в целях установления умысла лица в рамках расследования и судебного рассмотрения уголовных дел о преступлениях, предусмотренных ст. 282 УК РФ, назначаются различные судебные экспертизы, которые «становятся едва ли не ключевым источником информации, позволяющей отграничить экстремизм преступный от непреступного» [8, c. 7]. Кроме того в Методических рекомендациях Генеральной прокуратуры РФ от 29 июня 1999 г.
№ 27-19-99 «Об использовании специальных познаний по делам и материалам о возбуждении национальной, расовой или религиозной вражды» (далее - Рекомендации) отмечено, что в процессе расследования уголовного дела «главным объектом исследования и основным источником доказательств являются сам текст публикации, выступления, требующие содержательного анализа и юридической оценки».

В Рекомендациях дается перечень основных признаков, характеризующих возбуждение национальной, расовой или религиозной вражды с точки зрения общественной опасности, и отмечается, что «если в процессе проверки при содержательном анализе публикации будет выявлено, что текст или его часть прямо подпадают под один или несколько признаков, необходимо решать вопрос о возбуждении уголовного дела».

Таким образом, если лицо распространяет информационные материалы, признанные экстремистскими по решению суда, и включенные в опубликованный федеральный список экстремистских материалов (далее - Федеральный список; Список), то данное деяние, как показывает практика, зачастую квалифицируется как административное правонарушение. Если же распространяются материалы, не признанные экстремистскими по решению суда, и не включенные в Список, но с аналогичным содержанием, действия виновного в большинстве своем квалифицируются по ст. 282 УК РФ. В подтверждение сказанному приведем несколько примеров из судебной практики. Так, в конце июля 2007 г. В. Мильков создал в сети «Интернет» свой электронный дневник, в котором опубликовал текстовые сообщения, содержащие информацию, направленную на возбуждение ненависти, вражды, а также на унижение достоинства представителей Кавказа и Средней Азии, находящихся на территории России. Кроме того, В. Мильков опубликовал в своем электронном дневнике два указания (ссылки) на адреса (места расположения) в сети «Интернет» мультимедийного файла политического видеоролика пропагандистского характера под названием «Казнь таджика и дага. 2007 НСПР». В данном видеоролике была изображена сцена убийства двух мужчин южного типа. По уголовному делу была проведена комплексная программная компьютерно-техническая судебная экспертиза, которая установила, что «живой журнал» Милькова посетило не менее 140 пользователей сети «Интернет». В заключении комплексной социолого-психолингвистической судебной экспертизы было констатировано, что видеоролик и статьи со страницы «живого журнала» посредством психического заражения могут сформировать негативные и агрессивные установки и ана- 


\section{Административное и муниципальное право 8 (104) • 2016}

логичную мотивацию к деятельности у читателей, имеющих разную степень эмоциональной неустойчивости, личностных и других психических расстройств, в том числе и межнациональную вражду [9, с. 189-198].

Решением Майкопского городского суда от 27 мая 2008 г. страницы, созданного Мильковым в сети Интернет дневника - «живого журнала», и видеоролик под названием «Казнь таджика и дага. 2007 НСПР (Операция по аресту и казни двух колонистов из Дагестана и Таджикистана 2007 год)» признаны экстремистскими материалами (в Федеральном списке расположены под порядковыми номерами 264 и 265 соответственно).

Важно отметить, что от формального признания данного видеоролика экстремистским материалом его содержание и направленность не изменились. Складывается парадоксальная ситуация распространение уже запрещённых материалов, которые и без проведения многочисленных экспертиз, способны вызвать негативную установку, содержащих высказывания на возбуждение вражды, что установлено фактом включения их в Список - административное правонарушение. Следует отметить, что судебная практика в отграничении рассматриваемого уголовно-наказуемого деяния от административного правонарушения не отличается единообразием. В доказательство вышесказанного считаем необходимым привести следующие примеры. Так, Постановлением мирового судьи первого судебного участка Советского района г. Новосибирска студент одного из ВУЗов г. Новосибирска был признан виновным в совершении административного правонарушения, предусмотренного ст. 20.29 КоАП РФ [10]. Он бесплатно и для неограниченного круга лиц распространял через локальную сеть фильм, признанный решением Ленинского районного суда г. Кирова 29 августа 2007 г. и решением Приморского районного суда г. Санкт-Петербурга 28 июля 2008 г., экстремистским материалом (порядковый номер 101 в Списке).

Приведем другой пример. 14 января 2009 г. приговором Армавирского городского суда Краснодарского края М. признан виновным в совершении преступления, предусмотренного ч. 1 ст. 282 УК РФ. Так, М. в период до 14 марта 2007 г. приобрел не менее 261 экземпляров печатной брошюры с заголовком «Отдайте нам Родину! или ВОКЗАЛ - БАКУ (без чемоданов)» автора Монаха Афанасия. Ознакомившись с их содержанием, он перевез указанные брошюры с целью их распространения в г. Армавир. Зная о том, что брошюра содержит информацию, направленную на возбуждение ненависти, вражды, а также на унижение достоинства групп лиц по признаку национальности, происхождения, отношения к религии, М. действуя умышленно, с целью возбуждения у жителей Армавира национальной вражды и ненависти к другим нациям, сознавая и предвидя общественную опасность своих действий, создающих угрозу основам конституционного строя РФ и безопасности государства, склонил ранее знакомого ему К. к их распространению среди жителей Армавира.

Одним из доказательств виновности подсудимого М. в совершении указанного преступления явилась заверенная копия вступившего в законную силу решения Промышленного районного суда г. Ставрополя от 25 апреля 2008 г. о признании экстремистским материалом брошюры «Отдайте нам Родину! или ВОКЗАЛ - БАКУ (без чемоданов)» автора Монаха Афанасия.

В судебном заседании суд отметил, что действия подсудимого М. были правильно квалифицированы органами предварительного расследования. Суд также квалифицировал действия М. по ч. 1 ст. 282 УК РФ, поскольку в судебном заседании были установлены обстоятельства, свидетельствующие об умысле М. на совершение действий, направленных на возбуждение ненависти, вражды, унижение достоинства группы лиц по признакам национальности. Данные действия он совершил путем распространения брошюр с соответствующим содержанием среди жителей г. Армавира, то есть публично [9, с. 189-198].

Таким образом, в первом примере действия квалифицированы по ст. 20.29 КоАП РФ, поскольку распространялся экстремистский материал. Из второго приведенного примера следует, что обвиняемый М. ознакомился с содержанием брошюры и с целью распространения перевез её в количестве не менее 261 экземпляров в г. Армавир. В приговоре также указывалось и то, что данная брошюра признана экстремистским материалом по решению суда. Однако 4 марта 2009 г. Краснодарский краевой суд отменил обвинительный приговор, вынесенный М. По словам адвоката М., суд вынес такое решение на основании того, что в 2007 году, когда М. распространял эту книгу, она не была признана экстремистским материалом [11]. Следует отметить, что в ходе судебного разбирательства был доказан умысел М. на возбуждение среди жителей Армавира вражды и ненависти к представителям других национальностей.

Как видим, данное уголовное дело наглядно продемонстрировало, что единственный критерий отграничения правонарушения, предусмотренного ст. 20.29 КоАП РФ, от преступления, предусмотренного ст. 282 УК РФ, в виде направленности умысла лица, также является ненадежным.

Суммируя вышеизложенное, с учетом результатов анализа судебной практики по уголовным делам о преступлениях, предусмотренных ст. 282 
УК РФ, и по административным делам о правонарушениях, предусмотренных ст. 20.29 КоАП РФ, предлагаем:

1) из диспозиции ст. 20.29 КоАП РФ указание на такую форму объективной стороны состава как массовое распространение экстремистских материалов, включенных в опубликованный федеральный список экстремистских материалов, исключить;

2) дополнить главу 29 УК РФ статьей 282.4:

Статья 282.4. Распространение экстремистских материалов

1) массовое распространение экстремистских материалов, включенных в опубликованный федеральный список экстремистских материалов, -

наказывается ...

2) То же деяние, совершенное:

а) группой лиц;

б) с использованием служебного положения, наказывается ...

Санкции, предусмотренные за совершение преступлений, предусмотренных ч. 1 и ч. 2 ст. 282.4 УК РФ следует приравнять к санкциям, предусмотренным за совершение преступлений, предусмотренных ч. 1 и ч. 2 ст. 282 УК РФ.

Реализация данного законодательного предложения приведет к искусственной конкуренции вновь введенной ст. 282.4 УК РФ со ст. 280 и ст. 282 УК РФ. Для пояснения данного утверждения, смоделируем следующую ситуацию. Так, решением Московского районного суда г. Калининграда от 29 октября 2014 г. признано экстремистским материалом текстовое сообщение, размещенное на электронной странице в сети «Интернет» (порядковый номер 2628 Федерального списка). Если обратиться к тексту данного сообщения, которое цитируется в наименовании экстремистского материала, то можно обнаружить, что оно содержит призывы к осуществлению экстремистской деятельности. Следовательно, в случае криминализации массового распространения экстремистских материалов, лицо, его распространившее, должно будет подлежать ответственности по совокупности преступлений, предусмотренных ст. 280 и вновь введенной ст. 282.4 УК РФ. Тогда как лицо, распространившее текстовое сообщение с аналогичными призывами, не являвшегося ранее предметом судебного разбирательства, а, следовательно, еще не признанного экстремистским материалом, будет подлежать ответственности только по ст. 280 УК РФ. Вместе с тем общественная опасность данных деяний не имеет принципиальных отличий, чтобы усиливать ответственность виновного лица в первом из рассмотренных случаев путем его привлечения к уголовной ответственности сразу по двум преступле- ниям. Аналогичная ситуация может возникнуть и при распространении экстремистских материалов, содержащих информацию, направленную на возбуждение вражды по определенным в уголовном законе признакам (квалификация по совокупности преступлений, предусмотренных ст. 282 и вновь введенной ст. 282.4 УК РФ).

С целью недопущения искусственной конкуренции уголовно-правовых норм, представляется необходимым внести в УК РФ следующие изменения:

1) в статье 280:

часть первую после слов «экстремистской деятельности» дополнить словами: «а равно массовое распространение экстремистских материалов, включенных в опубликованный федеральный список экстремистских материалов, содержащих такие призывы»;

2) в статье 282 :

часть первую после слов: «в том числе сети «Интернет»» дополнить словами: «а равно массовое распространение экстремистских материалов, включенных в опубликованный федеральный список экстремистских материалов, содержащих информацию, направленную на возбуждение ненависти либо вражды, а также на унижение достоинства человека либо группы лиц по тем же признакам».

Изготовление и хранение экстремистских материалов для их последующего распространения будет образовывать приготовление к данным преступлениям. Однако уголовная ответственность за указанные действия не наступает, так как в соответствии с ч. 2 ст. 30 УК РФ лицо подлежит ответственности за приготовление только к тяжким и особо тяжким преступлениям. Данные преступления к указанным категориям не относятся. Таким образом, указанные деяния будут образовывать состав административного правонарушения, предусмотренного ст. 20.29 КоАП РФ, с учетом предложенных нами изменений ее редакции. Следовательно, внесение вышеуказанных изменений в УК РФ, не «породит» конкуренцию норм административного и уголовного права.

Следует отметить, что массовому распространению экстремистских материалов, включенных в опубликованный федеральный список, обязательно должен предшествовать следующий юридический факт: вступление в законную силу решения суда о признании информационного материала экстремистским. В связи с этим для настоящего исследования представляет интерес процедура формирования и содержание Федерального списка. Данный список размещен на официальном сайте Министерства юстиции РФ и по состоянию на 21 июля 2016 года включает в себя 3706 пун- 


\section{Административное и муниципальное право 8 (104) • 2016}

ктов. Не представляется возможным утверждать, что он состоит из 3706 наименований, поскольку наименования, расположенные под порядковыми номерами 262, 362-364, 413, 632-660, 667, 677-679, 682, 914, 915, 1284-1286, 1289, 1293-1304, 13071309, 1311, 1312, 1314-1318, 1320, 1321, 1323-1331, 1333-1335, 1341-1344, 1346-1351, 2020, 2103, 2342, $2343,2954,2980,2989$, были исключены. Таким образом, Список включает 3608 наименований.

Обращает на себя внимание то обстоятельство, что из Списка исключено 98 наименований, однако только в одном-единственном случае уточняется основание исключения информационного материала из Списка (исключены информационные материалы с порядкового номера 632 по порядковый номер 660 включительно). В данном случае указываются реквизиты определения суда (наименование суда, дата вынесения определения), на основании которого был произведен поворот исполнения решения суда о признании информационных материалов, расположенных в графах 632-660 включительно, экстремистскими материалами, путем исключения их из Списка. Кроме того уточняется, что под этими номерами были расположены информационные материалы Л. Рона Хаббарда. Однако непонятно в отношении каких конкретно информационных материалов было вынесено решение об их признании экстремистскими, которое впоследствии было отменено. Также в пунктах 667, 677679 и 682 есть уточняющие пометки, отсылающие к другим порядковым номерам Списка. Например, в графе напротив пункта 667 указано: «Запись исключена из списка (смотри № 616)». Представляется, что в данном случае запись была исключена, так как под пунктами 667 и 616 был расположен один и тот же экстремистский материал.

Однако, несмотря на то, что продублированные информационные материалы в отдельных случаях были исключены из Списка, Список очень громоздкий, тяжел для восприятия, и в нем сложно ориентироваться. Для сравнения приведем примеры: в аналогичном Списке Республики Беларусь содержится 3 CD-R диска, 27 книжных и 8 печатных изданий, а в Сингапуре запрещены все публикации Международной Ассоциации Исследователей Библии, Общества Сторожевой Башни, Библий и трактатов, а также 15 периодических изданий (журналов). Использование письменных материалов, опубликованных Международной Ассоциацией Исследователей Библии и Обществом Сторожевой Башни, Библий и трактатов, находится под запретом, поскольку на территории Сингапура запрещена деятельность таких религиозных организаций как «Свидетели Иеговы» и «Церковь объединения» в 1972 году и 1982 году соответственно. Особо следует отметить, что в Сингапуре закон, регламентирующий порядок признания информационных материалов запрещенными, под названием «0 нежелательных публикациях» был принят еще в 1967 году. Кроме того в Сингапуре в указанный перечень Списка нежелательных публикаций включены не только так называемые экстремистские материалы, но и информационные материалы, пропагандирующие секс, насилие, жестокость, употребление наркотических средств или других одурманивающих веществ [4, с. 61].

Основное функциональное назначение Федерального списка заключается в обеспечении знания лица о характере распространяемых (обнародуемых) им информационных материалов. Представляется, что по замыслу законодателя данный список должен был приобрести преюдициальное значение. Однако законодательством Российской Федерации определены так называемые «границы» судебного решения. Исходя из смысла соответствующих положений Гражданско-процессуального кодекса РФ, преюдициальная сила решения о признании материалов экстремистскими распространяется только на лиц, участвующих в деле. Следует согласиться с мнением, что действующее законодательство не исключает, а наоборот, обязывает «в каждом новом процессе с участием новых лиц, заново доказывать, что информационные материалы являются экстремистскими»[12, c. 8]. Именно этим и объясняется, почему некоторые информационные материалы признаются экстремистскими повторно. Например, уже упоминавшаяся нами брошюра Монаха Афанасия была признана экстремистским материалом решением Промышленного суда г. Ставрополя от 25 апреля 2008 г. и решением Майкопского районного суда Республики Адыгея от 26 июля 2012 г.

Более того указанные обстоятельства обусловливают и такую ситуацию, когда решением одного суда признается экстремистским информационный материал, который ранее решением другого суда таковым признан не был. Вместе с тем следует помнить, что признание информационного материала экстремистским влечет определенные правовые последствия, а именно, исключение его из свободного обращения на территории РФ. Таким образом, запрет распространять тот или иной экстремистский материал распространяется на все физические и юридические лица. В связи с этим возникают вполне логичные вопросы:

1) почему из двух судебных решений при решении вопроса об ответственности лица, распространяющего спорный информационный материал, должно применяться именно решение, которым этот материал был признан экстремистским, а не то, которым было отказано в признании его же экстремистским? 
2) Почему массовое распространение того или иного информационного материала, признанного судом экстремистским, и включенного в опубликованный федеральный список экстремистских материалов, влечет ответственность всех лиц, тогда как преюдициальное значение этого решения распространяется только на лиц, участвовавших в деле? Последнее обстоятельство, как было отмечено раннее, влечет признание одних и тех же информационных материалов экстремистскими несколько раз, что в свою очередь «утяжеляет» Федеральный список.

Для разрешения данной ситуации и устранения противоречивости судебных решений по одним и те же вопросам, а также их множественности представляется целесообразным внести изменения в гражданско-процессуальное законодательство, в соответствии с которыми преюдициальная сила решения о признании информационного материала экстремистским распространялась бы на всех лиц, в том числе и на лиц, не участвовавших в ранее рассмотренном деле. В случае реализации данного законодательного предложения необходимо решить вопрос о создании так называемого «белого» списка информационных материалов, в который должны быть включены материалы, в отношении которых судом вынесено решение об отказе в признании их экстремистскими.

Анализ содержания Федерального списка позволяет все экстремистские материалы классифицировать по следующим основаниям:

1) в зависимости от носителя информации:

бумажные экстремистские материалы (книги, журналы, газеты, листовки, альманахи, вестники, брошюры, альманахи, еженедельники);

- электронные экстремистские материалы (различного рода оптические диски (CD-R и DVD диски и др.), дискеты, WEB-сайты).

2) В зависимости от объективной формы выражения (представления) информации экстремистские материалы подразделяются на музыкальные произведения, литературные произведения, статьи, фильмы, рисунки, изображения, фотографии, отдельные высказывания, листовки.

3) В зависимости от психологического воздействия на потенциальных потребителей экстремистские материалы подразделяются на материалы, содержащие внушение, убеждение, призывы.

4) В зависимости от канала восприятия информации экстремистские материалы подразделяются на:

- визуальные материалы. Их содержание воспринимается потенциальным потребителем информации органами зрения (книги, тексты, рисунки, фотографии, и т.д. независимо от носителя информации);

- аудиальные материалы. Их содержание воспринимается только органами слуха (высказывания отдельных лиц, музыкальные произведения, различного рода обращения, в том числе машиночитаемые);

- аудиовизуальные материалы. Содержание данных материалов, воспринимается одновременно органами зрения и слуха (фильм, видеоролик и т.д.).

5) В зависимости от способа закрепления информации на информационном носителе можно выделить рукописные, печатные, магнитные, фотографические, оптические, лазерные и электронные экстремистские материалы.

Представленная классификация экстремистских материалов не является исчерпывающей.

Анализ содержания Федерального списка позволил сделать вывод, что судом зачастую признаются экстремистскими именно носители информации (например, дискеты, DVD диски) с дальнейшим уточнением расположенной на них информации, например, экстремистские материалы, расположенные под порядковыми номерами 33, 872 Федерального списка и др. Считаем, такой подход не вполне рациональным и несоответствующим легальному определению понятия экстремистских материалов. Логичнее было бы признавать экстремистским материалом информацию, находящуюся на том или ином носителе информации, например, как в описании информационного материала, расположенного под номером 691 Списка. Объясняется данное предложение тем, что диски, карты памяти, дискеты и т.д. - это носители информации. Получается, что если та или иная информация будет находиться на ином носителе, то формально это уже не экстремистский материал, так как в судебном решении признается экстремистским именно диск с информацией, а не информация на диске.

В связи с изложенным целесообразно дополнить постановление Пленума Верховного Суда РФ от 28 июня 2011 г. № 11 пунктом следующего содержания:

«В резолютивной части решения по делам о признании информационного материала экстремистским суду следует признавать экстремистским материалом не вид носителя информации (дискеты, CD-R, DVD диски и другие носители информации, предназначенные для использования в компьютерных устройствах, комплексах, системах и сетях), а объективную форму выражения (представления) произведения или иной информации (рукопись, видеозапись, фильм, музыкальное произведение, стихотворение, изображение, рисунок, 


\section{Административное и муниципальное право 8 (104) • 2016}

фотография, литературное произведение и др.) на том или ином носителе информации».

Кроме того судебная практика показала, что информационные материалы, признанные экстремистскими, например, в бумажном (печатном) виде, впоследствии могут быть воспроизведены полностью или частично на ином носителе информации, например, в виде аудиоматериала. К примеру, книга «Красная Каббала» признана экстремистским материалом решением Темрюкского районного суда Краснодарского края от 06 марта 2013 г. (порядковый номер 1957 в Списке), а 26 марта 2015 г. Кировским районным судом СанктПетербурга признан экстремистским материалом аудиоматериал «Григорий Климов «Красная Каббала», который содержит высказывания, цитирующие выдержки из книги «Красная Каббала» под авторством Г.П. Климова (порядковые номера 3195 и 3196 Списка). Получается, что дважды предметом судебного рассмотрения становился фактически один и тот же информационный материал, правда выраженный в другой объективной форме, и закрепленный на ином носителе информации. Считаем, что наличие такой возможности «обхода» закона рассредоточивает силы по противодействию экстремизму, и необоснованно расширяет Федеральный список. В Списке «вынуждено» дублируются, по сути, одни и те же информационные материалы.

Для устранения выявленного недостатка необходимо в Федеральный закон № 114-ФЗ внести следующие изменения:

1) статью 1 дополнить новым пунктом следующего содержания:
«3.1. Документы либо информационные материалы, воспроизводящие полностью или частично содержание экстремистского материала, включенного в опубликованный федеральный список экстремистских материалов, независимо от объективной формы выражения (представления) информации и носителя информации, являются теми же экстремистскими материалами, содержание которых они воспроизводят, и не требуют признания их таковыми в порядке ст. 13 настоящего Закона»;

2) второй абзац статьи 13 после слов «информационные материалы» дополнить следующими словами: «за исключением документов или информационных материалов, предусмотренных п. 3.1 настоящего Закона».

Внесение указанных изменений в Федеральный закон № 114-Ф3 позволит избежать множественности судебных решений по одним и тем же вопросам, и будет препятствовать необоснованному разрастанию Федерального списка.

Аккумулируя изложенное, можно сделать вывод, что Список имеет существенные недостатки, обозначенные в настоящем исследовании. Кроме того в Списке имеются ошибки (в том числе грамматические); отсутствует единство употребляемых терминов (в том числе при оперировании общепринятыми формулировками) и др. В связи с этим обязательным условием реализации предложения о криминализации массового распространения экстремистских материалов является систематизация и анализ материалов, признанных экстремистскими, и включенных в опубликованный федеральный список экстремистских материалов.

\section{Библиография:}

1. Федеральный закон от 25 июля 2002 г. № 114-Ф3 «О противодействии экстремистской деятельности» // СПС «КонсультантПлюс».

2. Бешукова 3.М. Преступления, связанные с осуществлением экстремистской деятельности: сравнительно-правовое исследование: автореф. дис. ... канд. юрид. наук. Ростов-на-Дону, 2011. 27 с.

3. Фридинский С.Н. Противодействие экстремистской деятельности (экстремизму) в России: социально-правовое и криминологическое исследование: автореф. дис. ... д-ра юрид. наук. М., 2011. 37 с.

4. Бешукова 3.М. Преступления, связанные с осуществлением экстремистской деятельности (сравнительно-правовое исследование): монография. Пятигорск: РИА-КМВ. - 2011. - 208 с.

5. Бешукова 3.М. Объект преступления, предусмотренного ст. 282 Уголовного Кодекса Российской Федерации: дискуссионные аспекты // Евразийский юридический журнал. 2012. № 1 (44). С. 105-106.

6. Курс Советского уголовного права в шести томах. M., 1970. T. IV. C. 187.

7. Постановление Пленума Верховного Суда РФ от 28 июня 2011 г. № 11 «0 судебной практике по уголовным делам о преступлениях экстремистской направленности» // СПС «КонсультантПлюс».

8. Погодин И.В.Заключение эксперта-ключевое средство доказывания по делам экстремистской направленности // Российский следователь. 2012. № 2. С. 7-10.

9. Бешукова 3.М. Уголовная и административная ответственность за массовое распространение экстремистских материалов: критерии разграничения // Профилактика экстремистской деятельности: проблемы и перспективы: материалы круглого стола / под общ. ред. Ф.М. Кобзарева, В.В. Меркурьева - М.: Акад. Ген. прокуратуры Рос. Федерации, 2014. - С. 189-198.

10. Официальный сайт прокуратуры Новосибирской области. URL: http://prokuratura-nso.ru/

11. URL: http://www.sova-center.ru/racism-xenophobia/news/counteraction/2009/03/d15419/ 
12. Султанов А.Р. Применение европейских стандартов в гражданском судопроизводстве на примере проблемы экстремистских дел // Адвокат. 2010. № 8. С. 7-28.

\section{References (transliterated):}

1. Federal'nyi zakon ot 25 iyulya 2002 g. № $114-\mathrm{FZ}$ «O protivodeistvii ekstremistskoi deyatel'nosti» // SPS «Konsul'tantPlyus».

2. Beshukova Z.M. Prestupleniya, svyazannye s osushchestvleniem ekstremistskoi deyatel'nosti: sravnitel'no-pravovoe issledovanie: avtoref. dis. ... kand. yurid. nauk. Rostov-na-Donu, 2011. $27 \mathrm{s.}$

3. Fridinskii S.N. Protivodeistvie ekstremistskoi deyatel'nosti (ekstremizmu) v Rossii: sotsial'no-pravovoe i kriminologicheskoe issledovanie: avtoref. dis. ... d-ra yurid. nauk. M., 2011. 37 s.

4. Beshukova Z.M. Prestupleniya, svyazannye s osushchestvleniem ekstremistskoi deyatel'nosti (sravnitel'no-pravovoe issledovanie): monografiya. Pyatigorsk: RIA-KMV. - 2011. - $208 \mathrm{~s}$.

5. Beshukova Z.M. Ob"ekt prestupleniya, predusmotrennogo st. 282 Ugolovnogo Kodeksa Rossiiskoi Federatsii: diskussionnye aspekty // Evraziiskii yuridicheskii zhurnal. 2012. № 1 (44). S. 105-106.

6. Kurs Sovetskogo ugolovnogo prava v shesti tomakh. M., 1970. T. IV. S. 187.

7. Postanovlenie Plenuma Verkhovnogo Suda RF ot 28 iyunya 2011 g. № 11 «0 sudebnoi praktike po ugolovnym delam o prestupleniyakh ekstremistskoi napravlennosti» // SPS «Konsul'tantPlyus».

8. Pogodin I.V. Zaklyuchenie eksperta - klyuchevoe sredstvo dokazyvaniya po delam ekstremistskoi napravlennosti // Rossiiskii sledovatel'. 2012. № 2. S. 7-10.

9. Beshukova Z.M. Ugolovnaya i administrativnaya otvetstvennost' za massovoe rasprostranenie ekstremistskikh materialov: kriterii razgranicheniya // Profilaktika ekstremistskoi deyatel'nosti: problemy i perspektivy: materialy kruglogo stola / pod obshch. red. F.M. Kobzareva, V.V. Merkur'eva - M.: Akad. Gen. prokuratury Ros. Federatsii, 2014. - S. 189-198.

10. Ofitsial'nyi sait prokuratury Novosibirskoi oblasti. URL: http://prokuratura-nso.ru/

11. URL: http://www.sova-center.ru/racism-xenophobia/news/counteraction/2009/03/d15419/

12. Sultanov A.R. Primenenie evropeiskikh standartov $v$ grazhdanskom sudoproizvodstve na primere problemy ekstremistskikh del // Advokat. 2010. № 8. S. 7-28. 